\title{
Synthesis of Nonlinear Control of Switching Topologies of Buck-Boost Converter Using Fuzzy Logic on Field Programmable Gate Array (FPGA)
}

\author{
Johnson A. Asumadu, Vaidhyanathan Jagannathan, Arkhom Chachavalnanont
}

Electrical and Computer Engineering, Western Michigan University, Kalamazoo, USA.

Email: johnson.asumadu@wmich.edu

Received September $25^{\text {th }}, 2009$; accepted January $11^{\text {th }}, 2010$.

\begin{abstract}
An intelligent fuzzy logic inference pipeline for the control of a dc-dc buck-boost converter was designed and built using a semi-custom VLSI chip. The fuzzy linguistics describing the switching topologies of the converter was mapped into a look-up table that was synthesized into a set of Boolean equations. A VLSI chip-a field programmable gate array (FPGA) was used to implement the Boolean equations. Features include the size of RAM chip independent of number of rules in the knowledge base, on-chip fuzzification and defuzzification, faster response with speeds over giga fuzzy logic inferences per sec (FLIPS), and an inexpensive VLSI chip. The key application areas are: 1) on-chip integrated controllers; and 2) on-chip co-integration for entire system of sensors, circuits, controllers, and detectors for building complete instrument systems.
\end{abstract}

Keywords: Multi-Fuzzy Logic Controller (MFLC), Field Programmable Gate Array (FPGA), Buck-Boost Converter, Boolean Look-Up Table, Co-Integration

\section{Introduction}

The design of control laws for power converters and inverters has been based mainly on linear control theory. However, most power electronics switching topologies have variable structures which are non-linear, characterized by discontinuities, and are therefore more difficult to model. The three most popular control methods used are state-space averaging technique [1], variable structure control (VSC) [2], and sliding mode control [3]. The state-space technique may lead to instability, the VSC control has hysteresis as drawback, and the sliding-mode control is very complicated. The implementation of the above-mentioned control laws are complicated, high cost and almost not practical.

Fuzzy logic controllers (FLCs) are very suitable for variable structures but current applications of FLCs use software for implementation. However, hardware implementation will be cheaper and faster. The proposed method combines hybrid linguistic models used in FLCs and computational paradigms of Boolean algebra. The knowledge base of the converter switching topologies is used to form a look-up table which is described by Boolean equations which are easily implemented using FPGA. Results showed that the size of the FPGA is in- dependent of the number inference rules in the knowledge base, speeds in giga FLIPS are achieved because it is hardware based, and very fast control response.

\section{Proposed Method}

\subsection{Single-Input-Single-Output (SISO) Fuzzy Controller}

Consider the generalized buck-boost converter shown in Figure 1. This is a single-input-single-output (SISO) system. The input variable is the capacitor voltage $\left(v_{\mathrm{C}}\right)$ and the output variable is the duty ratio $D$. It can be shown that the average model has the following equations:

$$
\begin{aligned}
& \frac{d i_{L}(t)}{d t}=\frac{(1-D) v_{C}(t)}{L}+\frac{D E}{L} \\
& \frac{d v_{C}(t)}{d t}=\frac{(1-D) i_{L}(t)}{C}-\frac{v_{C}(t)}{C R}
\end{aligned}
$$

The membership functions for $v_{\mathrm{C}}$ and $D$ are shown in Figure 2. The SISO system of Figure 1 has a single fuzzy input $V\left(v_{\mathrm{C}}\right)$ and a single fuzzy output $D$.

The fuzzy membership sets $V$ and $D$ are represented by five linguistic qualifiers $L$ (low), $M L$ (medium low), $O K$ (okay), $\mathrm{MH}$ (medium high), and $H$ (high). Hence there 


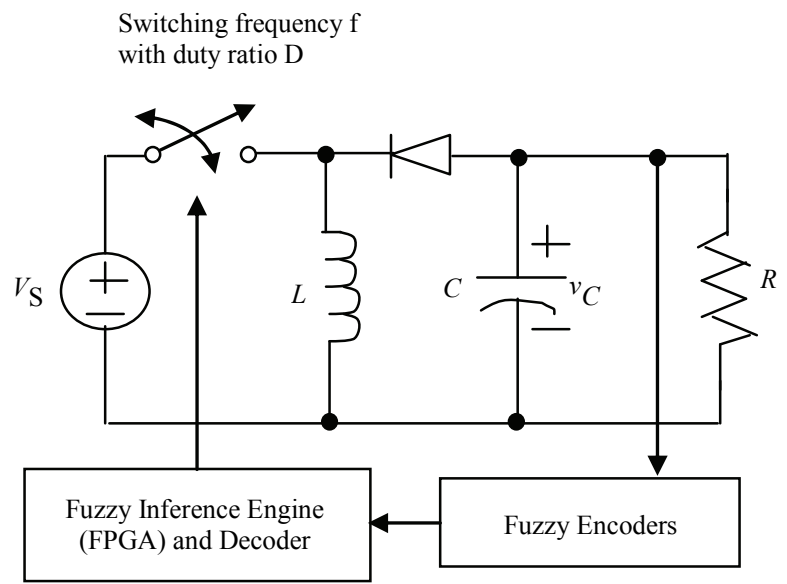

Figure 1. Buck-boost switching converter with a fuzzy controller

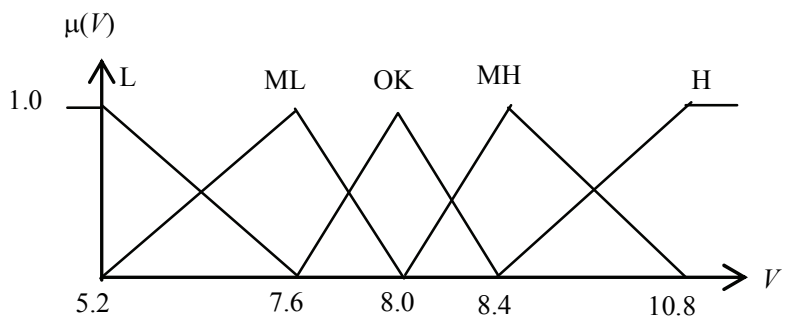

(a)

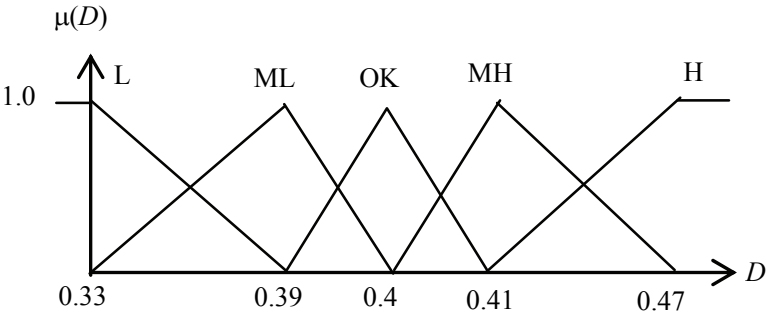

(b)

Figure 2. Membership functions for (a) voltage and (b) duty ratio

are $5 \times 5=25$ possible combinations that can generate 25 possible rules. However, the following 5 rules are sufficient to describe the membership values of Figure 2.

$\begin{array}{ll}\text { RULE 1: } & \text { IF } V \text { is } H \text {, THEN } D \text { is } L \\ \text { RULE 2: } & \text { IF } V \text { is } M H \text {, THEN } D \text { is } M L \\ \text { RULE 3: } & \text { IF } V \text { is } O K, \text { THEN } D \text { is } O K \\ \text { RULE 4: } & \text { IF } V \text { is } M L, \text { THEN } D \text { is } M H \\ \text { RULE 5: } & \text { IF } V \text { is } L, \text { THEN } D \text { is } H\end{array}$

\subsection{Logic Synthesis of Fuzzy Controllers}

Consider a SISO fuzzy controller with input universe of discourse $A^{1}$ and output universe of discourse $B^{1}$. Manzoul [4] showed that the number of unique fuzzy inputs (ufi) is equal to the dimension of the input universe of discourse. That is:

$$
\mathrm{ufi}=\operatorname{dim}\left[A^{1}\right]=\mathrm{q}_{1}
$$

In the fuzzification process, each input is mapped into only one value (one element) in the input universe of discourse and zero value to all other values (elements). The objective here is to use a look-up table. Therefore, the number of rows in the look-up table is equal $\mathrm{q}_{1}$. It was also shown in [4] that the total least integer number of binary bits $X$ for all the inputs is given by

$$
X=\log _{2} \mathrm{q}_{1}
$$

Each fuzzy input has only one output value and therefore the maximum number of distinct output values is also equal to $\mathrm{q}_{1}$. In the defuzzification process only one element is selected in the output universe of discourse. It is therefore, easier and economical to use the defuzzified 
outputs in the look-up table. If the there are $p$ elements ( $p$ $\leq q_{1}$ ) in the output universe of discourse, the dimension of the output universe of discourse is given as

$$
\operatorname{dim}\left[B^{1}\right]=\mathrm{p}
$$

The total least integer number of binary bits $Y$ for all the outputs is given by

$$
Y=\log _{2} \mathrm{p}
$$

\section{Buck-Boost Converter Fuzzy Controller}

\subsection{Fuzzy Controller}

Consider a SISO controller to control the output voltage of the buck-boost converter of Figure 1. The input variable is the voltage and output variable is the duty ratio. The duty ratio maintains the voltage at a selected value. The ranges of capacitor voltage $\left(v_{\mathrm{C}}\right)$ and duty ratio $\mathrm{D}$ are (5.2 to 10.8$) \mathrm{V}$ and $(0.33$ to 0.47$)$ respectively. The membership values are in the interval $[0,1]$, where 0 denotes no membership and 1 denotes full membership. Assume that

$$
\operatorname{im}\left[V^{1}\right]=\operatorname{dim}\left[D^{1}\right]=29
$$

From (5) the least number of binary bits to represent the input values is given as

$$
X=\log _{2} \quad 29=5
$$

Similarly, using (6) the least number of binary bits to represent output values is given as

$$
Y=\log _{2} \quad 29=5
$$

In Appendix I the 5 rules of (3) are expressed numerically. The fuzzy relation obtained is too big to be shown here because of the size (29x29 matrix). Table 1 of Appendix I shows the summary of the complete computations of the controller.

\subsection{Look-Up Table}

The look-up table representing the fuzzy controller is given in Table 2. The input universe of discourse has dimension of 29 and the output universe has dimension

\begin{tabular}{|c|c|c|c|}
\hline Input Voltage & Fuzzified Input & Fuzzy Output & Output Duty Ratio (X) \\
\hline $0.0-5.20$ & $1.0,0.0,0.0, ., ., ., 0.0$ & $* 0,0, .08, .16, .25, .33, .41, .5, .58, .66, .75, .83, .91,1.0$ & 120 \\
\hline $5.21-5.40$ & $0.0,1.0,0.0, ., ., ., 0.0$ & $*, .08, .08, .08, .16, .25, .33, .41, .5, .58, .66, .75, .83, .91, .91$ & 118 \\
\hline $5.41-5.60$ & $0.0, ., ., 1.0, ., ., ., 0.0$ & $*, .16, .16, .16, .16, .25, .33, .41, .5, .58, .66, .75, .83, .83, .83$ & 116 \\
\hline $5.61-5.80$ & $0.0, ., ., 1.0, ., ., ., 0.0$ & $*, .25, .25,, .25,, .25,, .25, .33, .41, .58, .66, .75, .75, .75, .75$ & 114 \\
\hline $5.81-6.00$ & $0.0, ., ., 1.0, ., ., ., 0.0$ & * $.33, .33, .33, .33, .33, .33, .41, .5, .58, .66, .66, .66, .66, .66$ & 111 \\
\hline $6.01-6.20$ & $0.0, ., ., 1.0, ., ., ., 0.0$ & $*, .41, .41, .41, .41, .41, .41, .41, .5, .58, .58, .58, .58, .58, .58$ & 109 \\
\hline $6.21-6.40$ & $0.0, ., ., 1.0, ., ., ., 0.0$ & $*, .5, .5, .5, .5, .5, .5, .5, .5, .5, .5, .5, .5, .5, .5$ & 106 \\
\hline $6.41-6.60$ & $0.0, ., ., 1.0, ., ., ., 0.0$ & $*, .5, .58, .58, .58, .58, .58, .58, .5, .41, .41, .41, .41, .41, .41, .41$ & 103 \\
\hline $6.61-6.80$ & $0.0, ., ., 1.0, ., ., ., 0.0$ & $*, .5, .66, .66, .66, .66, .66, .58, .5, .41, .33, .33, .33, .33, .33$ & 101 \\
\hline $6.81-7.00$ & $0.0, ., ., 1.0, . ., ., ., 0.0$ & $*, .5, .75, .75, .75, .75, .66, .58, .5, .41, .33, .25,, .25,, .25,, .25$ & 99 \\
\hline $7.01-7.20$ & $0.0, ., ., 1.0, . ., ., ., 0.0$ & $*, .5, .83, .83, .83, .75, .66, .58, .5, .41, .33, .25, .16, .16, .16$ & 98 \\
\hline $7.21-7.40$ & $0.0, ., ., 1.0, . ., ., ., 0.0$ & $*, .5, .91, .91, .83, .75, .66, .58, .5, .41, .33, .25, .16, .08, .08$ & 97 \\
\hline $7.41-7.60$ & $0.0, ., ., 1.0, . ., ., ., 0.0$ & * $, .5,1.0, .91, .83, .75, .66, .58, .5, .41, .33, .25, .16, .08, .0$ & 96 \\
\hline $7.61-7.80$ & $0.0, ., ., 1.0, . ., ., ., 0.0$ & $* *, .5, .5, .5, .5, .5, .5, .5, .5, .5, .5, .41, .33, .25, .16, .08,0.0$ & 94 \\
\hline $7.81-8.00$ & $0.0, ., ., 1.0, ., ., ., 0.0$ & $* *, .5,1.0, .5, * *$ & 70 \\
\hline $8.01-8.20$ & $0.0, ., ., 1.0, . ., ., ., 0.0$ & $0, .08, .16, .25, .33, .41, .5, .5, .5, .5, .5, .5, .5, .5, .5, .5, * *$ & 45 \\
\hline $8.21-8.40$ & $0.0, ., ., 1.0, . ., ., ., 0.0$ & $0, .08, .16, .25, .33, .41, .5, .58, .66, .75, .83, .91,1.0, .5, *$ & 43 \\
\hline $8.41-8.60$ & $0.0, ., ., 1.0, . ., ., ., 0.0$ & $.08, .08, .16, .25, .33, .41, .5, .58, .66, .75, .83, .91, .91, .5 * *$ & 42 \\
\hline $8.61-8.80$ & $0.0, ., ., 1.0, . ., ., ., 0.0$ & $.16, .16, .16, .25, .33, .41, .58, .66, .75, .75, .75, .75, .5, *$ & 41 \\
\hline $8.81-9.00$ & $0.0, ., ., 1.0, . ., ., ., 0.0$ & $.25,, .25,, .25,, .25, .33, .41, .58, .66, .75, .75, .75, .75, .5 * *$ & 40 \\
\hline $9.01-9.20$ & $0.0, ., ., 1.0, . ., ., ., 0.0$ & $.33, .33, .33, .33, .33, .41, .5, .58, .66, .66, .66, .66, .66, .5, *$ & 38 \\
\hline $9.21-9.40$ & $0.0, ., ., 1.0, . ., ., ., 0.0$ & $.41, .41, .41, .41, .41, .41, .5, .58, .58, .58, .58, .58, .58, .5 * *$ & 36 \\
\hline $9.41-9.60$ & $0.0, ., ., 1.0, ., ., ., 0.0$ & $.5, .5, .5, .5, .5, .5, .5, .5, .5, .5, .5, .5, .5, .5,^{*}$ & 33 \\
\hline $9.61-9.80$ & $0.0, ., ., 1.0, . ., ., ., 0.0$ & $.58, .58, .58, .58, .58, .58, .5, .41, .41, .41, .41, .41, .41, .41, *$ & 30 \\
\hline $9.81-10.00$ & $0.0, ., ., 1.0, . ., ., ., 0.0$ & $.66, .66, .66, .66, .66, .58, .5, .41, .33, .33, .33, .33, .33, .33 *$ & 28 \\
\hline $10.01-10.20$ & $0.0, ., ., 1.0, \quad ., ., ., 0.0$ & $.75, .75, .75, .75, .66, .58, .5, .41, .33, .25,, .25,, .25,, .25, .25 * *$ & 25 \\
\hline $10.21-10.40$ & $0.0, \quad ., \quad ., 1.0,0.0,0.0$ & $.83, .83, .83, .75, .66, .58, .5, .41, .33, .25, .16, .16, .16, .16 *$ & 23 \\
\hline $10.41-10.60$ & $0.0, \quad ., \quad ., 0.0,1.0,0.0$ & $.91, .91, .83, .75, .66, .58, .5, .41, .33, .25, .16, .08, .08, .08 *$ & 21 \\
\hline $10.61-10.8$ & $0.0, \quad ., \quad ., 0.0,0.0,1.0$ & $1.0, .91, .83, .75, .66, .58, .5, .41, .33, .25, .16, .08, .0, .0, *$ & 20 \\
\hline
\end{tabular}
of 29. The look-up can be described by 7-variable Boolean equations. That is,

$$
\begin{aligned}
& f 0=\sum(5,6,8,9,10,12,16,17,1923,26,27,28) \\
& f 1=\sum(2,4,5,7,8,10,11,14,17,18,21,24,27) \\
& f 2=\sum(2,3,5,6,8,9,14,15,16,21,22,24,25,27,28,29) \\
& f 3=\sum(1,5,6,7,14,16,17,18,19,20,24,25,26) \\
& f 4=\sum(1,2,3,4,14,24,25,26,27,28,29) \\
& f 5=\sum(1,2,3,4,5,6,7,8,9,10,11,12,13,16,17,18,19,20, \\
& 21,22,23) \\
& f 6=\sum(1,2,3,4,5,6,7,8,9,10,11,12,13,14,15)
\end{aligned}
$$

Table 1. Summary of the controller computations 
Table 2. Look-up table for fuzzy controller

\begin{tabular}{|c|c|c|c|c|c|c|c|c|c|c|c|c|c|}
\hline \multicolumn{6}{|c|}{ INPUT } & \multicolumn{8}{|c|}{ OUTPUT } \\
\hline \multirow[t]{2}{*}{$\#$} & \multicolumn{5}{|c|}{ BINARY } & \# & \multicolumn{7}{|c|}{ BINARY } \\
\hline & $y_{4}$ & $y_{3}$ & $y_{2}$ & $y_{1}$ & $y_{0}$ & & $f_{6}$ & $f_{5}$ & $f_{4}$ & $f_{3}$ & $f_{2}$ & $f_{1}$ & $f_{0}$ \\
\hline 1 & 0 & 0 & 0 & 0 & 1 & 120 & 1 & 1 & 1 & 1 & 0 & 0 & 0 \\
\hline 2 & 0 & 0 & 0 & 1 & 0 & 118 & 1 & 1 & 1 & 0 & 1 & 1 & 0 \\
\hline 3 & 0 & 0 & 0 & 1 & 1 & 116 & 1 & 1 & 1 & 0 & 1 & 0 & 0 \\
\hline 4 & 0 & 0 & 1 & 0 & 0 & 114 & 1 & 1 & 1 & 0 & 0 & 1 & 0 \\
\hline 5 & 0 & 0 & 1 & 0 & 1 & 111 & 1 & 1 & 0 & 1 & 1 & 1 & 1 \\
\hline 6 & 0 & 0 & 1 & 1 & 0 & 109 & 1 & 1 & 0 & 1 & 1 & 0 & 1 \\
\hline 7 & 0 & 0 & 1 & 1 & 1 & 106 & 1 & 1 & 0 & 1 & 0 & 1 & 0 \\
\hline 8 & 0 & 1 & 0 & 0 & 0 & 103 & 1 & 1 & 0 & 0 & 1 & 1 & 1 \\
\hline 9 & 0 & 1 & 0 & 0 & 1 & 101 & 1 & 1 & 0 & 0 & 1 & 0 & 1 \\
\hline 10 & 0 & 1 & 0 & 1 & 0 & 99 & 1 & 1 & 0 & 0 & 0 & 1 & 1 \\
\hline 11 & 0 & 1 & 0 & 1 & 1 & 98 & 1 & 1 & 0 & 0 & 0 & 1 & 0 \\
\hline 12 & 0 & 1 & 1 & 0 & 0 & 97 & 1 & 1 & 0 & 0 & 0 & 0 & 1 \\
\hline 13 & 0 & 1 & 1 & 0 & 1 & 96 & 1 & 1 & 0 & 0 & 0 & 0 & 0 \\
\hline 14 & 0 & 1 & 1 & 1 & 0 & 94 & 1 & 0 & 1 & 1 & 1 & 1 & 0 \\
\hline 15 & 0 & 1 & 1 & 1 & 1 & 70 & 1 & 0 & 0 & 0 & 1 & 1 & 0 \\
\hline 16 & 1 & 0 & 0 & 0 & 0 & 45 & 0 & 1 & 0 & 1 & 1 & 0 & 1 \\
\hline 17 & 1 & 0 & 0 & 0 & 1 & 43 & 0 & 1 & 0 & 1 & 0 & 1 & 1 \\
\hline 18 & 1 & 0 & 0 & 1 & 0 & 42 & 0 & 1 & 0 & 1 & 0 & 1 & 0 \\
\hline 19 & 1 & 0 & 0 & 1 & 1 & 41 & 0 & 1 & 0 & 1 & 0 & 0 & 1 \\
\hline 20 & 1 & 0 & 1 & 0 & 0 & 40 & 0 & 1 & 0 & 1 & 0 & 0 & $\begin{array}{l}1 \\
0\end{array}$ \\
\hline 21 & 1 & 0 & 1 & 0 & 1 & 38 & 0 & 1 & 0 & 0 & 1 & 1 & 0 \\
\hline 22 & 1 & 0 & 1 & 1 & 0 & 36 & 0 & 1 & 0 & 0 & 1 & 0 & 0 \\
\hline 23 & 1 & 0 & 1 & 1 & 1 & 33 & 0 & 1 & 0 & 0 & 0 & 0 & 1 \\
\hline 24 & 1 & 1 & 0 & 0 & 0 & 30 & 0 & 0 & 1 & 1 & 1 & 1 & 0 \\
\hline 25 & 1 & 1 & 0 & 0 & 1 & 28 & 0 & 0 & 1 & 1 & 1 & 0 & 0 \\
\hline 26 & 1 & 1 & 0 & 1 & 0 & 25 & 0 & 0 & 1 & 1 & 0 & 0 & 1 \\
\hline 27 & 1 & 1 & 0 & 1 & 1 & 23 & 0 & 0 & 1 & 0 & 1 & 1 & 1 \\
\hline 28 & 1 & 1 & 1 & 0 & 0 & 21 & 0 & 0 & 1 & 0 & 1 & 0 & 1 \\
\hline 29 & 1 & 1 & 1 & 0 & 1 & 20 & 0 & 0 & 1 & 0 & 1 & 0 & 0 \\
\hline
\end{tabular}

\subsection{Control Instrument Implementation}

\subsubsection{FPGA Implementation}

The FPGA configuration is implemented by using Xilinx's X95 (XC9536-10-PC44 CPLD) and XS40 (XC40 05XL FPGA) boards. Both boards come with $8051 \mathrm{mi}-$ crocontroller with $12 \mathrm{MHz}$ speed. The Xilinx's development system is used to implement the Boolean equations, which also represents the fuzzy controller. Figure 3 shows the semi-custom VLSI chip of the FPGA functional block diagram.

\subsubsection{Instrument}

Figure 4 shows the diagram of the fuzzy logic controller

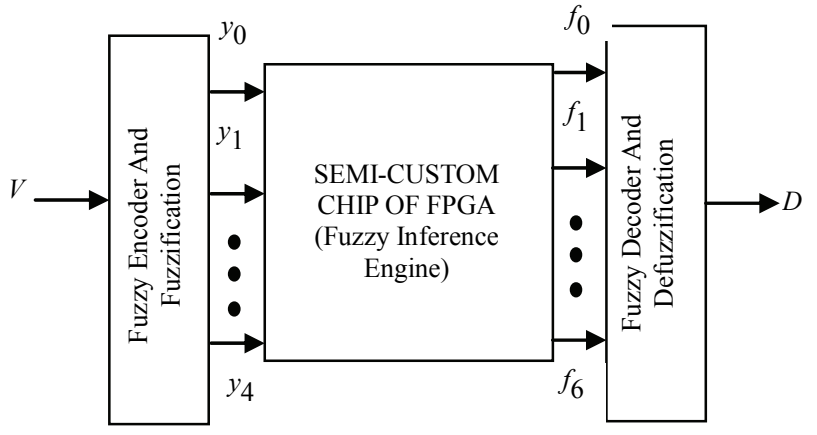

Figure 3. Semi-custom VLSI fuzzy controller chip chip pin outs and output waveforms. The binary inputs of the controller $y_{0}, y_{1}, \ldots, y_{4}$ are the encoded fuzzified crisp output voltage $v_{\mathrm{C}}$ of the dc-dc converter. The binary outputs of the controller $f_{0}, f_{1}, \ldots, f_{6}$ are defuzzified to provide the variable duty ratio $D$.

\subsubsection{On-Chip Cointegration}

Microsystems technology has made inroads in instrumentation and measurement (I\&M) applications. The fuzzy logic FPGA controller chip can be fabricated to have compact size. The FLC chip of this paper provides an interesting fabrication technique that has been identified in I\&M applications: cointergration of control/sensors/detectors and circuits for building complete instrument systems.

The on-chip controller mentioned in the paper uses a compact FPGA chip, which can be fabricated as part of an integrated system of sensors, circuits, controllers, and detectors squeezed onto nanometer wafer. Such microchips can be used in a variety of applications in different environments and requirements. Besides mass volume production of these microchips, there are other advantages such as cheaper parts and assembly of instruments, better functionality, lower mass and size, speed of control, lower cost, and higher efficiency. Some companies are now using multi fuzzy logic controller-based (MFLC) chips in some of their new dryers, dishwashers, and washing machines. 


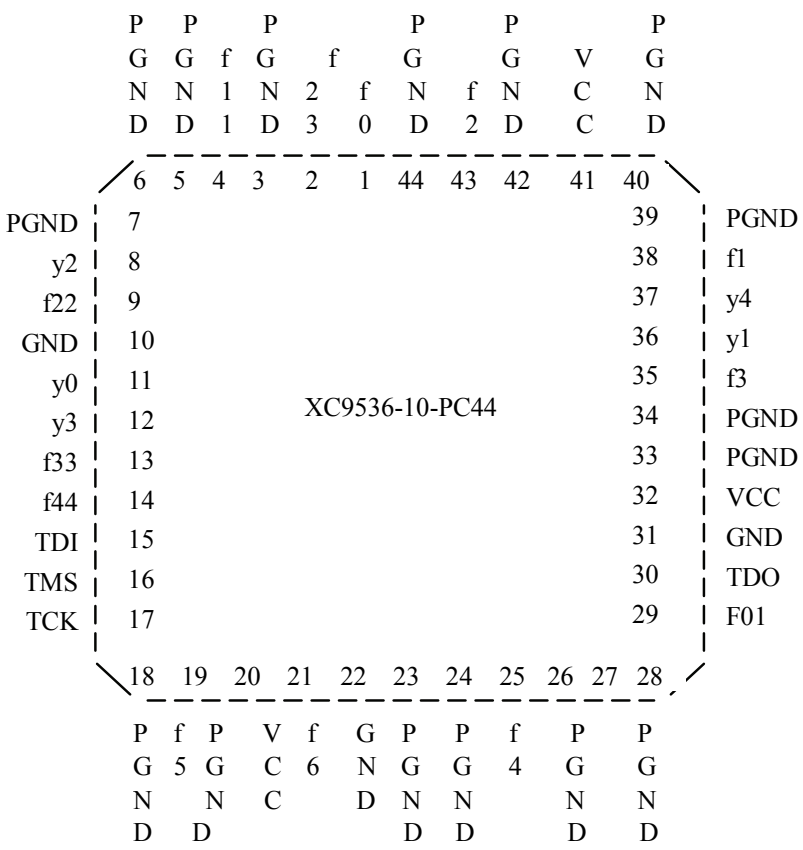

Legend : PGND $=$ Tie pin to GND for additional ground path or leave unconnected

$\mathrm{VCC}=$ Dedicated Power Pin

GND $=$ Dedicated Ground Pin

TDI = Test Data In, JTAG pin

TDO $=$ Test Data Out, JTAG pin

TCK = Test Clock, JTAG pin

TMS = Test Mode Select, JTAG pin

PROHIBITED = User reserved pin

(a)

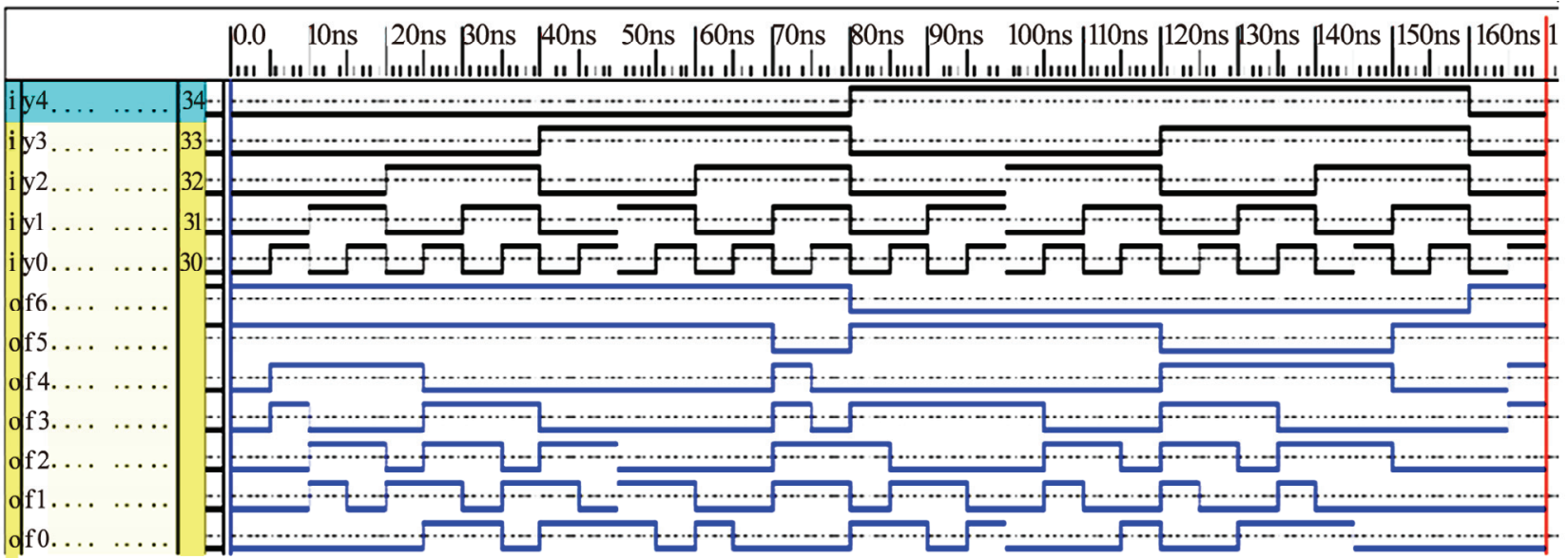

(b)

Figure 4. (a) FPGA pin out; (b) input and output waveforms of FLC chip

\section{Results}

The output voltage of Figure 1 is regulated at about $8.0 \mathrm{~V}$ through a feedback loop using the fuzzy controller on FPGA chip for adjusting the duty ratio $D$. The input voltage $V_{\mathrm{s}}=12 \mathrm{~V}$ and the circuit parameters are $L=100 \mu \mathrm{H}$, $C=330 \mu \mathrm{F}$. The steady-state voltage is about $8.0 \mathrm{~V}$ when the load $\mathrm{R}$ is changed from $10 \Omega$ to $5 \Omega$. Figure 5 shows the test results of a fuzzy controller chip. 


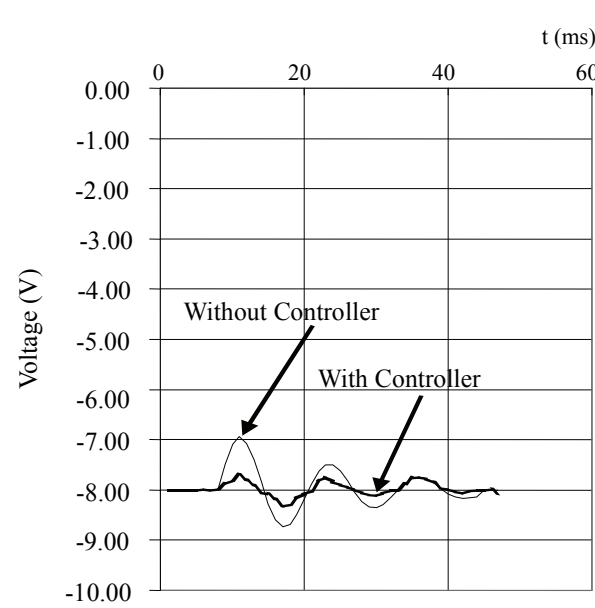

(a)

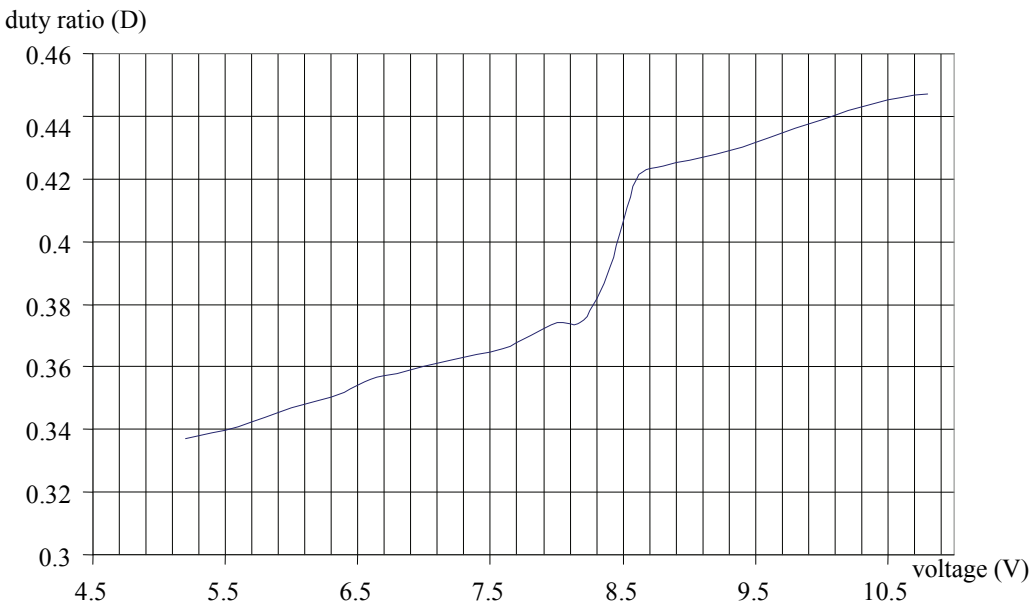

(b)

freq. $(\mathrm{Hz})$

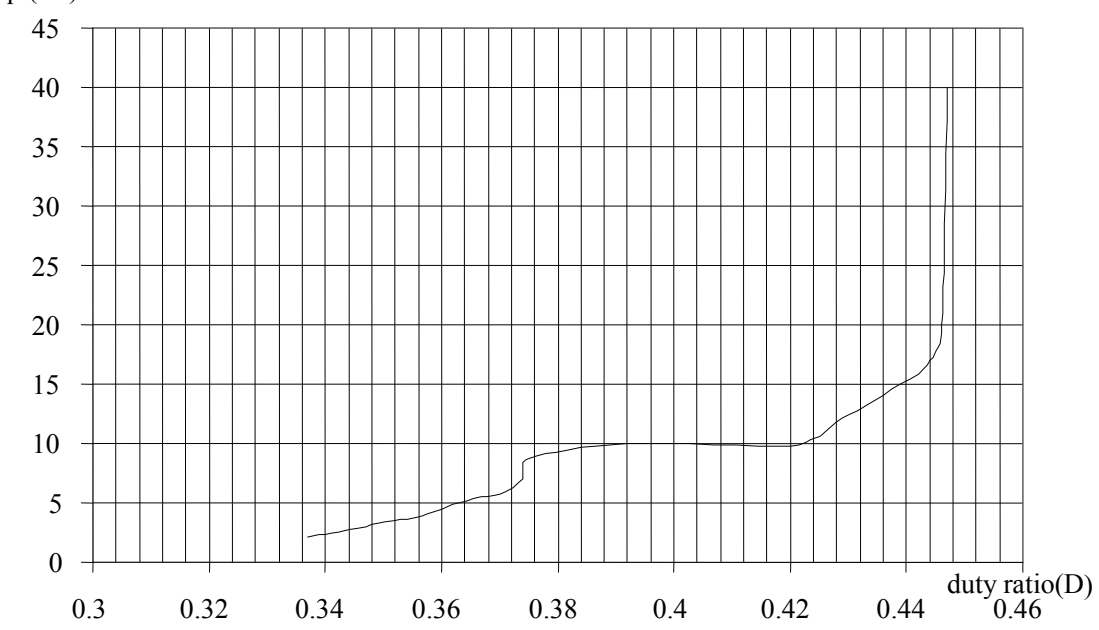

(c)

Figure 5. (a) Buck-boost converter results; (b) graph between voltage \& duty; (c) relationship of frequency \& duty ratio

Figure 5(a) shows the effect on the output voltage when changing the load resistance. Figure 5 shows that the output voltage $v_{\mathrm{c}}(\mathrm{t})$ can respond instantaneously to changes in the duty ratio $D$. The hardware implementation is cheaper and faster than using software.

\section{Conclusions}

The fuzzy controller implemented on an FPGA was used to control a dc-dc buck-boost switching converter. The size of the semi-custom VLSI was independent of the number of rules in the knowledge base and therefore no memory space was required to store the large of rules. The important aspect of the controller is that it was hardware-based and consequently speeds over giga FLIPS can be achieved. The on-chip controller is a compact FPGA which may be integrated with sensors and circuits to provide a complete co-integration system.

\section{REFERENCES}

[1] R. Erickson, S. Cuk, and R. D. Middlebrook, "Largesignal modeling and analysis of switching regulators," IEEE PESC, pp. 240-250, 1982.

[2] W. Gao and J. C. Hung, "Variable structure control of non-linear systems," IEEE Transactions on Industrial Electronics, Vol. 40, No. 1, pp. 45-55, February 1993.

[3] H. Sira-Ramirez and M. Rios Bolivar, "Sliding-mode control of DC-DC power converters via extended-linearization," IEEE Transactions on Circuits and Systems I, Vol. 41, No. 10, 1994.

[4] M. A. Manzoul, "Fuzzy controllers on semi-custom VLSI chips," Fuzzy Control Systems, CRC Press, Inc., Boca Raton, Florida, pp. 551-560, 1994. 


\section{APPENDIX I}

The 5 Rules of Equation 3 Expressed Numerically

RULE 1:

IF

$[0,0,0,0,0,0,0,0,0,0,0,0,0,0,0,0,0,0.08,0.16,0.25,0.33,0.41$

$, 0.5,0.58,0.66,0.75,0.83,0.91,1.0]$

THEN

$[1.0,0.91,0.83,0.75,0.66,0.58,0.5,0.41,0.33,0.25$, $0.16,0.08,0,0,0,0,0,0,0,0,0,0,0,0,0,0,0,0,0]$

RULE 2:

IF

$[0,0,0,0,0,0,0,0,0,0,0,0,0,0,0,0.5,1.0,0.91,0.83,0.75,0.66$, $0.58,0.5,0.41,0.33,0.25,0.16,0.08,0]$

THEN

$[0.08,0.16,0.25,0.33,0.41,0.5,0.58,0.66,0.75,0.83$, $0.91,1.0,0.5,0,0,0,0,0,0,0,0,0,0,0,0,0,0,0]$
RULE 3:

IF

$[0,0,0,0,0,0,0,0,0,0,0,0,0,0.5,1.0,0.50,0,0,0,0,0,0,0,0,0,0,0,0]$ THEN

$[0,0,0,0,0,0,0,0,0,0,0,0,0,0.5,1.0,0.50,0,0,0,0,0,0$, $0,0,0,0,0,0]$

RULE 4:

IF $\quad[0.08,0.16,0.25,0.33,0.41,0.5,0.58,0.66,0.75,0.83$, $0.91,1.0,0.5,0,0,0,0,0,0,0,0,0,0,0,0,0,0,0]$

THEN $[0,0,0,0,0,0,0,0,0,0,0,0,0,0,0,0.5,1.0,0.91,0.83$, $0.75,0.66,0.58,0.5,0.41,0.33,0.25,0.16,0.08,0]$

RULE 5:

IF $\quad[1.0,0.91,0.83,0.75,0.66,0.58,0.5,0.41,0.33,0.25$, $0.16,0.08,0,0,0,0,0,0,0,0,0,0,0,0,0,0,0,0,0]$

THEN $[0,0,0,0,0,0,0,0,0,0,0,0,0,0,0,0,0,0.08,0.16,0.25$, $0.33,0.41,0.5,0.58,0.66,0.75,0.83,0.91,1.0]$ 